\title{
100 anys de Carmelina Sánchez-Cutillas
}

\author{
100 years of Carmelina Sánchez-Cutillas
}

\author{
M. Isabel Guardiola SAVAlL \\ maribel.guardiola@ua.es \\ Universitat d'Alcacant - Acadèmia Valencian de la Llengua
}

Enguany fa cent anys del naixement de Carmelina Sánchez-Cutillas, la dona independent, rebel i bohèmia que entre els anys seixanta i començaments dels huitanta ens va regalar quatre llibres de poesia publicats, l'exquisida novel la Matèria de Bretanya i un generós volum de treballs d'investigació que va difondre en congressos, premsa periòdica i llibres diversos. El reconeixement com a Escriptora de l'Any el 2020, prorrogat al 2021, per part de l'Acadèmia Valenciana de Llengua ha (re)mogut l'interés sociocultural i la investigació entorn a la seua figura i obra en totes les seues facetes, sovint ombrejades per l'enlluernadora Matèria de Bretanya (1976), guanyadora del Premi Andròmina de Narrativa el 1975.

La crisi sanitària que ha protagonitzat les nostres vides en aquests dos anys de commemoració no ha enterbolit, però, les distintes iniciatives que s'han posat en marxa per divulgar ('fer que (una cosa) siga coneguda per un gran nombre de persones') qui va ser Carmelina Sánchez-Cutillas. Els reconeixements i les commemoracions tenen aquesta funció i, en el cas de Carmelina SánchezCutillas, ha representat, a més, un acte de justícia necessari. Així doncs, a iniciativa de l'Acadèmia Valenciana de la Llengua i també d'altres institucions i entitats que s'hi han volgut sumar, s'ha pogut visitar una exposició fixa al Centre del Carme entre el setembre i el novembre del 2020, circula prèvia comanda una exposició itinerant molt sovint acompanyada d'un club de lectura, s'ha elaborat material didàctic, s'ha projectat un documental i un llarg etcètera d'accions diverses. I entre aquestes activitats, la recerca al voltant de la seua obra i el context en què va viure i escriure ha ocupat dues jornades acadèmiques (una al setembre del 2020 i una altra que tancarà l'Any al novembre del 2021), un volum monogràfic d'estudis coordinat per Joan Borja i M. Àngels Francés que arreplega l'anàlisi i les reflexions de distints especialistes, $i$, finalment, el que constitueix el fermall d'or: l'edició de l'obra completa de prosa i poesia, també a càrrec de Borja i Francés, que inclourà tota l'obra publicada i també la inèdita que es guarda en el llegat dipositat en la Biblioteca Valenciana Nicolau Primitiu. 


\section{Isabel Guardiola Savall. 100 anys de Carmelina Sánchez-Cutillas}

És així, doncs, com el dossier que presentem, «100 anys de Carmelina Sánchez-Cutillas», constitueix també una peça clau en aquest engranatge de la investigació entorn a l'obra de l'autora i suma treballs i esforços a aquesta voluntat de redimensionar la figura de Sánchez-Cutillas i inserir-la en el lloc que li escau en el cànon dels estudis literaris. Els articles que s'hi insereixen aborden aspectes fins ara no tractats o bé tractats molt tangencialment per la crítica literària. Les perspectives d'estudi que hi trobem són diverses, però ocupa un lloc privilegiat l'anàlisi de l'obra poètica des de diversos prismes.

Així doncs, en primer lloc, l'article de Verònica Cantó Doménech (Acadèmia Valenciana de la Llengua), "Genealogia femenina en Els jeroglifics i la pedra de Rosetta (1976) de Carmelina SánchezCutillas», suposa una incursió en el penúltim poemari publicat de la nostra autora, Els jeroglifics $i$ la pedra de Rosetta (1976), un exercici poètic d'alta densitat simbòlica i conceptual, poc tractat per la crítica, segurament a causa de la dificultat d'interpretació. No obstant això, Cantó Doménech desgrana la simbologia present en la recreació i el lligam present en l'aparició dels personatges femenins inserits en els «jeroglífics» $\mathrm{i}$ ens convida a una interpretació de per què aquestes catorze figures universals recorren aquest llibre de prosa poètica.

D’altra banda, Irene Mira Navarro (Universitat d'Alacant) i Noèlia Díaz Vicedo (Queen Mary University of London) ens conviden a un exercici de literatura comparada entre Carmelina SánchezCutillas i dues figures cabdals de la poesia catalana contemporània: Vicent Andrés Estellés i Maria Mercè Marçal. Inicialment, Mira Navarro explora en «Apunts per a una lectura de la poètica de la resistència en Carmelina Sánchez-Cutillas i Vicent Andrés Estellés» la poesia dels seixanta d'aquests dos poetes a partir de la perspectiva d'anàlisi que li ofereix l'estudi de la poètica de la resistència, amb la qual pot vincular la veu poètica dels autors amb la presa de consciència de l'entorn social en què viuen i amb la consideració de la funció social que ambdós atorguen a la seua poesia. Seguidament, Díaz Vicedo analitza en «Riuen les meduses: cos i desig a la poesia de Carmelina Sánchez-Cutillas i Maria-Mercè Marçal» els lligams existents entre la poesia d'ambdues poetesses que, malgrat haver viscut en èpoques diferents, traspuen en els seus versos la mateixa experiència vital que les amera, la condició de ser dona i tot el que açò comporta i, també, la recreació i el pes de l'herència cultural transmesa.

I si de poetes va la cosa, tanca aquesta incursió a l'anàlisi de l'obra poètica, el treball de Begoña Pozo Sánchez (Universitat de València), que ens ofereix en «Les hereves de la poesia de Carmelina Sánchez-Cutillas (o sobre la fractura entre generacions literàries)» una visió realment nova des de l'òptica que s'han fet fins ara els estudis sobre l'autora: l'anàlisi de la recepció de l'obra a partir d'una enquesta feta a vint poetesses valencianes actuals, que la presenten com a un referent literari, malgrat les dificultats d'accedir a la seua obra, derivades fonamentalment, del fenomen de la criptogínia que ha patit aquesta autora i també altres escriptores de la seua generació.

Des d'un altre punt de vista totalment diferent, l'article de Joan Borja Sanz (Universitat d'Alacant), «Aportacions i referències etnopoètiques en l'obra de Carmelina Sánchez-Cutillas», focalitza la 
mirada en un aspecte que havia passat sovint inadvertit en la revisió de l'obra carmeliniana: les aportacions i les referències etnopoètiques que trobem difuminats en tota l'obra literària, però que especialment són notoris en Matèria de Bretanya (contes universals, llegendes, cançons i personatges fantàstics, entre altres).

Finalment, Josep Vicent Garcia Sebastià (Universitat d'Alacant) analitza en «La llengua en l'obra narrativa de Carmelina Sánchez-Cutillas: vers la construcció d'un model de referència al País Valencià» un altre aspecte, molt sovint anomenat, però encara mai no acabat de sistematitzar: des de la idea que Matèria de Bretanya va ser el primer llibre llegit en valencià per a una generació de valencians, descriu el model lingüístic de la novel la i del relat curt «El llamp i la sageta de records» i observa que, des de l'estil personal de l'autora que conjumina formes valencianes formals i dialectalismes del parlar de la Marina, convergeix amb la resta de lletraferits valencians de l'època i cerca la màxima convergència amb la resta de parlars del nostre idioma.

Heus ací, doncs, sis articles d'investigació diversos que tracten de cobrir i d'ampliar el coneixement i la reflexió sobre Carmelina Sánchez-Cutillas, una figura i una obra que no naix aillada sinó que es troba plenament inserida en el context sociocultural, històric i literari en què va viure i que esdevé també un referent a les hores d'ara. Benvingut, doncs, siga aquest dossier, especialment en aquest Any de commemoració del centenari del seu naixement. 